DOI: $10.17516 / 1997-1370-0687$

УДК 004.9(536.5)

\title{
A Quantative Approach to Identifying Factors that Affect the Use of E-Wallets in Bahrain
}

\author{
Muwafaq M. AlKubaisi and Nedaa Naser* \\ University of Bahrain \\ Sakhir, Southern Governorate, Bahrain
}

Received 12.06.2020, received in revised form 29.08.2020, accepted 10.11.2020

\begin{abstract}
Bahrain is considered the regional leader in the banking and finance sector. The e-wallet is one of the successful innovative services that was launched in 2017. The stage of identifying factors of the initial adoption of new technology is essential, but not enough as the technology provider company needs to focus on and understand the factors that affect the use and the continuity of use of e-wallet in order to maintain and sustain the user in the long term. A quantitative survey approach based on a 5-point Likert scale was used in this study. The sampling tool relies on the snowball and convenience sampling technique. The sample consisted of 660 users in Bahrain. The research used SmartPLS and SPSS software to analyze the collected data from the survey. The Structural Equation Modeling (SEM) was used to master the multiple relationships that exist between the four predictor variables [ease of use, compatibility, usefulness, and security], the satisfaction with e-wallet, continuous use of e-wallet and the demographical variables.

This study found that the four predictor variables are statistically significant and supportive. The compatibility variable is the leading factor in the analysis. However, the study's results indicated that the moderating variables were also found to be statistically insignificant.

The research findings contribute to the service providers and marketers with a clear understanding of the factors that affect the use of e-wallets and continuance use. Also, there was an addition to the theoretical implications indicated by the significant direct relationship between continuance use and compatibility.
\end{abstract}

Keywords: e-wallet, quantitative, Likert, SmarlPLS, SPSS, SEM, multilabel regression, predictor variables.

Research area: economy.

Citation: AlKubaisi, M.M., Naser N. (2020). A quantative approach to identifying factors that affect the use of e-wallets in Bahrain. J. Sib. Fed. Univ. Humanit. Soc. Sci., 13(11), 1819-1839. DOI: $10.17516 / 1997-1370-0687$.

(C) Siberian Federal University. All rights reserved

* Corresponding author E-mail address: buch 53@mail.ru 


\section{Introduction}

The growing number of smartphone users eventually would shift the mobile from being accessory to necessity. The user behavior is subjected to the new trends that come on the floor; individuals are attracted by technological advances that enable them to perform transactions more comfortably and faster (Garrett et al., 2014).

Although there are several approaches to encourage an individual to adopt new technology, the decision to continuance use of technology relies more on the post-adoption behaviour factors that affect the individual continuance intention to use something rather than on the initial adoption decision (Venkatesh \& Thong, 2012). In order to succeed and gain competitive advantage among others, the technology provider company needs to identify the benefits of the technology owned by an in-depth understanding of user behaviour (Tam, 2018; Bhattacherjee, 2001b). According to Albashrawi \& Motiwalla (2019), Manikandan \& Chandramohan (2016), and Hsiao (2016), the technology provider company needs to focus primarily on understanding the continuance intention factors to widen their services, support and retain users in the long run.

The overall trend moves towards using electronic wallets (e-wallets) that allow secure storage of bank card information on the mobile to be used to complete different transactions such as paying bills, transferring funds, and shopping (Singh et al., 2017). Moreover, users can place any information in the mobile wallet, such as identification cards, student IDs, credit cards, debit cards, and driver licenses (Swilley, 2010).

Globally, Apple Pay is the pioneer in e-wallet business that launched in 2014, followed by Google Pay and Samsung Pay to enable users to pay to the shops (Dimitrii, 2018) securely. However, the forecasted adoption of the e-wallet was higher than the number of actual users (Webster, 2018). The number of users of smartphones is expected to increase by $7 \%$ every year; China, India, and the US are the countries with the highest smartphone user scope - 1.3 billion, 530 million, and 229 million users, respectively. Moreover, the mobile payment volume was expected to be one trillion US dollars in 2019. Therefore, mobile commerce was expected to grow (statistics, 2016).

According to Singh et al. (2017), Indian youth are attracted to e-wallet and prefer to use it more than paying in cash because they enjoy the use of new mobile technologies. The competition is intense between the providers of the e-wallets service due to the low switching cost (Cao et al., 2018). Therefore, investigating the factors that affect the use and continuance use of e-wallet is important (Cao et al., 2018).

Bahrain is considered the regional leader in the banking and finance sector (Benefit, 2017). The global trend towards cashless measures has motivated the Kingdom of Bahrain to move forward and introduce the Electronic Fund Transfer System (EFTS) by the Benefit Company in 2015 (CBB, 2019). Nevertheless, the EFTS enables individuals to perform transactions and provide fast and secure fund transfer; the ability to pay bills immediately, almost with no mistakes, occurs throughout three services available, which are Fawri+ Fawri and Fawateer (CBB, 2019).

Kingdom of Bahrain is heading to become a Financial Technology (FinTech) centre in the region (CBB, 2019). In October 2017 Central Bank of Bahrain (CBB) established a FinTech unit to proceed towards FinTech, which is responsible for the quality of the services provided to clients, which include approval given to participants in the FinTech as well as monitoring and supervision responsibilities. Moreover, the CBB has issued several guidelines, regulations policy, and a series of measures to regulate and facilitate the implementation of FinTech. The FinTech unit helps develop the existing financial environment by attracting national, regional, and international FinTech companies to the Kingdom of Bahrain (CBB, 2019).

One of the highlighted developments of FinTech is the successfully launched e-wallet in the Kingdom of Bahrain. The use of e-wallets will change how individuals interact with money (CBB, 2019) as the physical cards and actual cash is replaced by e-wallets that enable users to settle their payments and transfer funds electronically by waving or scanning the 
Table 1. Volume of Transactions in Bahrain

\begin{tabular}{|c|c|c|c|}
\hline \multicolumn{2}{|c|}{ Period } & Volume & Value (BD) \\
\hline \multirow{3}{*}{2018} & Quarter 1 & 56,438 & 474,199 \\
\cline { 2 - 4 } & Quarter 2 & 165,869 & $2,795,996$ \\
\cline { 2 - 4 } & Quarter 3 & 340,411 & $8,070,273$ \\
\cline { 2 - 4 } & Quarter 4 & 571,939 & $18,072,712$ \\
\hline \multirow{2}{*}{2019} & Quarter 1 & 955,540 & $31,899,530$ \\
\cline { 2 - 4 } & Quarter 2 & $1,382,762$ & $65,981,116$ \\
\hline
\end{tabular}

codes via smartphones. The digital society provides a network of connected and collaborated entities that are CBB, bank entities, telecommunication companies, shopping stores, and individuals (CBB, 2019).

The below Table 1 is extracted from the Central Bank of Bahrain (CBB); it shows that the volume of transactions in the second quarter of 2018 increased from 0.166 million to almost 1.4 million in the second quarter of 2019. The amount of value (BD) dramatically increased from almost BD 2.8 million in the second quarter of 2018 and almost reached BD 66 million in the second quarter of 2019.

The significant growth in the quarterly volume of transactions, as well as the amount of value (BD) in 2019 compared to 2018, is due to the widespread acceptance in going cashless and the launch of e-wallets in 2017 (CBB, 2019).

The success of e-wallets in the Kingdom of Bahrain can be reviewed in numbers, for example, BenefitPay, which is one of the e-wallets in the Kingdom of Bahrain. The volume of transactions recorded in the first half of 2018 was almost 12 thousand, while this volume reached 806 thousand in the first half of 2019. Moreover, the amount of value (BD) dramatically increased from BD 0.7 million in the first half of 2018 to BD 55.2 million in the first half of 2019 (CBB, 2019).

According to CBB (2019), simple, quick, and easy to conduct transactions in one place is the reason for e-wallet usage growth. The e-wallet initiative is going to enhance user experience as the Kingdom of Bahrain is progressing towards the cash-less and card-less approach.
The e-wallet service activation is done by installing the application to the mobile set. It is followed by applicant registration, which requires the name and phone number, copying the Postal Index Number (PIN) code, that is received through Short Message Service (SMS), to the applicant, and entering card details in the application.

\section{Literature Review}

Based on the focus area presented in the introduction, e-wallet service is viewed as an innovative idea (Singh et al., 2017), and it was launched in the Kingdom of Bahrain by Benefit company in May 2017 (CBB, 2019). In the Kingdom of Bahrain, payment solution services continue to grow through expanding services, upgrading the features, enhancing position in the market, and adding new services to e-wallet. For example, in 2019, VIVA and National Bank of Bahrain (NBB) amde a new partnership to launch a new service that would enable the user to withdraw cash from the STC wallet (STC, 2019).

Mobile payment services enable users to perform financial transactions anytime and anywhere, using their smartphone devices (Tam et al., 2018; Chen \& Wu, 2017). The mobile payment transactions that can be performed in stores or even out stores consist of paying for purchasing goods and services, paying bills, and instantly transferring funds (Chen \& Wu, 2017).

According to Cao et al. (2018), there are two types of mobile payment services concerning the place of origin of the service. The first type of mobile payment service is the service that was already available on comput- 
ers such as AliPay.com, which become AliPay wallet on the mobile version. In contrast, the second type is mobile payment service that initially launched from mobile, such as WeChat payment, the social network service provider. In the Kingdom of Bahrain, bWallet is an example of the first type of mobile payment service that was already available on computers as batelco.com. However, BenefitPay is an example of the second type of mobile payment service that was initially launched for the mobile devices.

The mobile payment service is done via mobile devices or smartphones, and its characteristics are discussed by (Chen \& Wu, 2017). The prime instrument used is the smartphone device that enables making remote transactions anytime and anywhere by using e-wallets. The obstacles of mobile payment services include security issues and the availability of the necessary devices to conduct the transactions in stores (Chen \& Wu, 2017).

E-wallet is equivalent to the physical wallet that holds the money (Manikandan \& Chandramohan, 2016). It is defined as a virtual wallet that allows users to place any information in the mobile wallet, such as identification cards, student IDs, credit cards, debit cards, and driver licenses. In other words, secure storage includes personal information, bank information, payment history, and shopping details on the mobile to be used to manage, review and complete different transactions such as paying bills, transferring funds, and shopping (Singh et al., 2017; Swilley, 2010).

The preference towards using an e-wallet is higher than that of the traditional method, and e-wallet is convenient to users as they are satisfied with the easiness of using e-wallet and the transaction speed (Singh et al., 2017). The key advantage of using the new advanced technology is that it allows users to access their financial and perform transactions quickly. This was illustrated earlier in the Table 1, as there was significant growth in the volume of transactions and the amount of value (BD) in 2019 compared to 2018, the reasons mentioned by the CBB (2019) are the widespread acceptance in going cashless, and the launch of e-wallets in 2017.
The use of e-wallet seems to be attractive to users, and they prefer to use it instead of another mode of payment due to the facilities provided, such as promotional offers, loyalty points, cashback benefits, and alike (Singh et al., 2017). Also, individuals feel it more convenient and efficient when using mobile payment instead of online payment (Cao et al., 2018).

The theory in the quantitative approach is defined as a group or set of interrelated dependent and independent variables that shape the research hypotheses or propositions by defining the magnitude or direction of relationships between variables in order to explain specific phenomena (Creswell, 2013).

Several models and theories investigate the continuance use of e-wallet such as the Technology Acceptance Model (TAM) and Expectancy-Confirmation Model (ECM), below is an in-depth discussion of the post-adoption theories and models.

There are many implementations of Technology Acceptance Model (TAM) in previous studies, Alaeddin et al. recognize it (2018) as the widely used model due to its simplicity (Kwateng, 2019; Farah et al., 2018; Tam et al., 2018; Chen \& Wu, 2017).

Initially, this model focuses on technology adoption as it was implemented by Akturan \& Tezcan (2012). Also, TAM indicates the actual use, which is determined by consumer intention; Yuan (2016) implemented it. However, the implantation of TAM is very generic, as Alaeddin (2018) applied TAM to examining the users switching intention and behaviour. Moreover, Chang et al. (2013) applied TAM to investigating continuance use.

TAM was used in almost $67 \%$ of research studies published in 2017 (Alaeddin et al., 2018). The number of studies that implemented TAM in examining the factors that affect the post-adoption usage concluded that the usefulness and ease of use are either directly or indirectly affect the post-adoption usage, especially in mobile banking. (Avornyo, 2019; Albashrawi \& Motiwalla, 2019; Yuan et al., 2016; Amin et al., 2012).

As shown in Fig. 1 above, the model consists of perceived ease of use and perceived usefulness; these two constructs are serving 


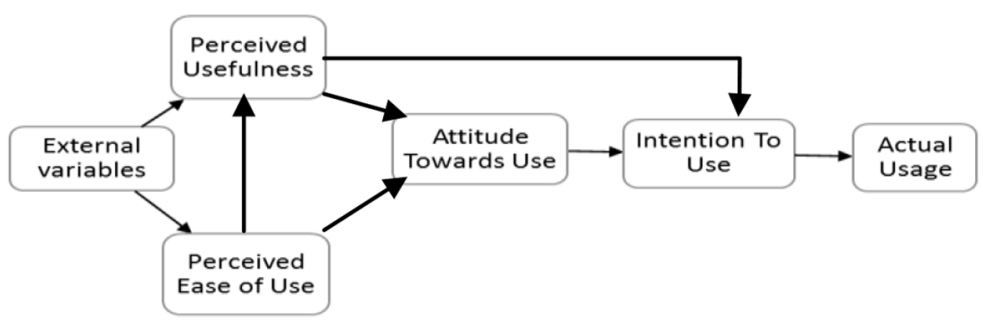

Fig. 1. Technology Acceptance Model

as a determinant of individual attitude and behavioural intention towards using the technology (Venkatesh \& Davis, 1996). This research incorporates the two primary constructs to gain a better understanding of the factors affecting the continuance use of e-wallet.

Oliver (1980) developed a consumer behaviour model called Expectancy-Confirmation Theory (ECT) that is commonly used to explain consumer satisfaction (Chou, 2013). According to Kumar (2018), ECT is an extension of the TAM model; it proves the ability to investigate the continuance use of the service or product.

The ECM was recognized as the most suitable model to investigate the post-adoption intentions and continuance usage to sustain and retain users in the long term (Tam et al., 2018). Also, it is recognized as the dominant model to investigate the continuance usage of mobile banking services (Avornyo et al., 2019).

In Expectancy-Confirmation Theory (ECT), consumer satisfaction is determined by both expectation and perceived performance. The confirmation is an indication of the degree to which the expectation is confirmed by comparing it to the performance (Chou et al., 2013).

The Expectancy-Confirmation Model (ECM) was introduced in the spot of ECT by Bhattacherjee (2001a). The ECM is useful in understanding the continuance use factors in the technologies related to the mobile (Avornyo et al., 2019). Consumer satisfaction, as shown in Fig. 2 below, is determined by both perceived usefulness and confirmation (Yuan et al., 2016).

The confirmation is the usage benefits that users expect to obtain through technology ex- perience (Tam et al., 2018). The expectations and experience determine the user confirmation of expectations. Thus, the positive effect on user satisfaction is determined by both the confirmation of expectations and the positive effect on the perceived usefulness. The confirmation of expectations is the usage benefits that users anticipate to gain; thereby, it positively affects the perceived usefulness and user satisfaction.

In the spotlight of the ECM model, this research adopts the relationships that exist in the model as follows: First, the direct relationship between usefulness and continuance use. Second, the indirect relationship that exists between usefulness and continuance use through satisfaction. Last, the direct relationship between satisfaction and continuance use.

The theories were set together, the TAM was recognized as the generally used model (Alaeddin et al., 2018) and the ECM was recognized as the most suitable method to investigate the post-adoption intentions and continuance usage (Tam et al., 2018; Kumar, 2018). The ECM assumes a change in initial expectations after adoption (Avornyo et al., 2019).

The integration of both TAM and ECM has formed the bases, and they were extensively used to investigate the continuance usage intention (Avornyo et al., 2019; Albashrawi \& Motiwalla, 2019; Yuan et al., 2016; Boakye, 2012; Hong, 2006). However, TAM and ECM are functioning better when they are implemented separately (Avornyo et al., 2019).

The ECM suggests that continuance use is governed by consumer satisfaction and perceived usefulness and confirmation. However, the ECM is not comprehensive as more factors are affecting the continuance use (Yuan et al., 


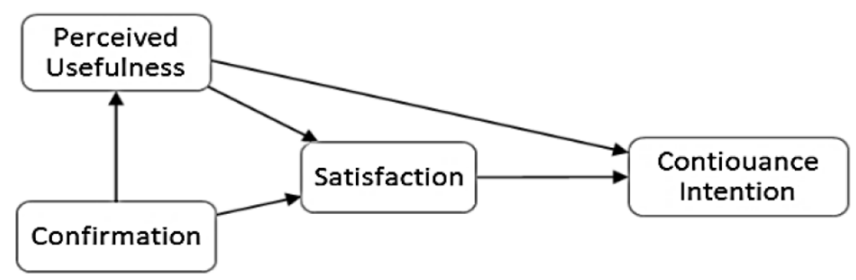

Fig. 2. Expectancy-Confirmation Model

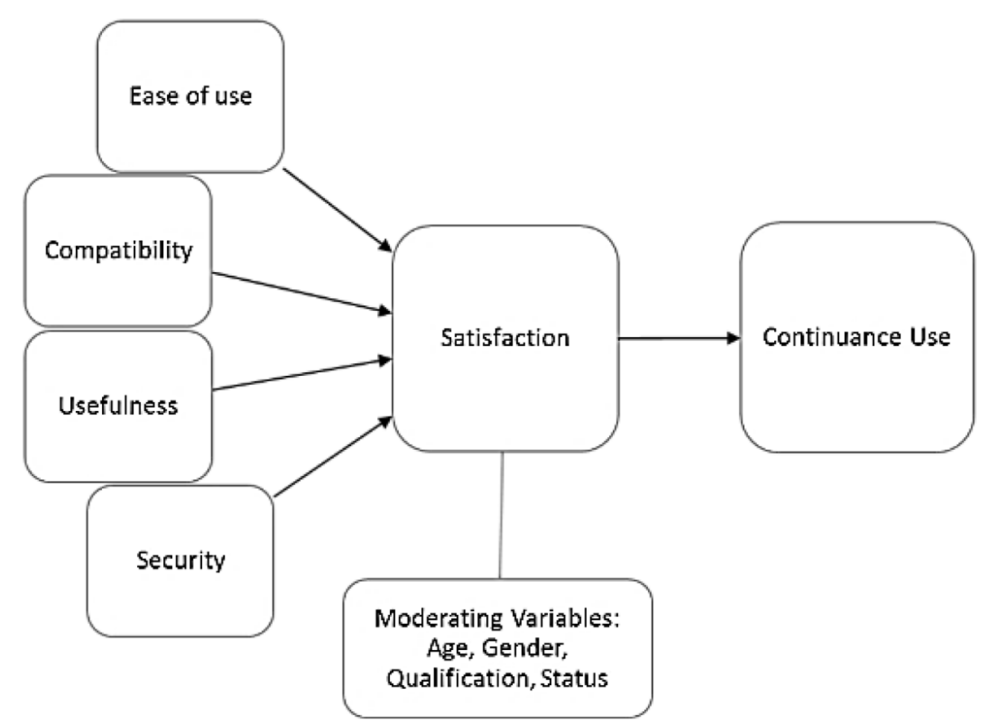

Fig. 3. Research Model

2016). TAM was integrated into the ECM to investigate more factors. Consequently, this research model and hypotheses were developed based on the integration of both TAM and ECM.

This research employs satisfaction, usefulness, and ease of use to enhance the understandability of the main factors that affect the use and continuance use of e-wallet. Moreover, this research model introduces two new vital predictors, the security and the compatibility, along with demographic characteristics.

\section{Research Model}

The study's proposed model is based on the integration of both ECM and TAM. ECM is widely used to explain user satisfaction (Chou et al., 2013). In contrast, TAM is usually used for many purposes, such as explaining the adoption of technology (Alaeddin et al., 2018), indicating the actual usage (Yuan et al., 2016), and investigating continuance use of technology (Chang et al., 2013).

The integration of both models was designed to identify which of the below factors (Fig. 3) are influencing user satisfaction (actual usage) and continuance use of e-wallet in the Kingdom of Bahrain. The combination of ECM and TAM represents the variable relationships used to answer these research questions.

The extracted variables from the integration of ECM and TAM are the "ease of use," "usefulness," "user satisfaction," and "continuance use." The "continuance use" is predicted by the overall satisfaction level (Cao et al., 2018; Kumar et al., 2018; Chou et al., 2013). The research model supports that satisfaction is a predictor of the "continuance use," and there is a positive association between satisfaction and e-wallet continuance use. 
Moreover, the addition of the two new constructs to this research model was aimed at testing the impact of the constructs on satisfaction and continuance use of e-wallet. The two constructs are compatible, which is one of the essential factors when it comes to using technology (Bagla \& Sancheti, 2018) and security constructs, which is the primary concern and critical factor when it comes to dealing with financial transactions (Kumar et al., 2018).

The moderating demographic variables that consist of age, gender, educational qualification and the employment status were added to the model. It is used to test the moderating role of user demographic characteristics in the relationship between the satisfaction concerning the use of e-wallet and the four predictor variables (ease of use, compatibility, usefulness, and security).

The research model is derived from the focused research objectives and research questions. The research model is presented below (Fig. 3).

\section{Research Hypotheses}

After the stage of setting the research objectives, research questions, and the research model, the researcher formulates relevant hypotheses that initially explain the situation or interpret variables, or describe cause and effect relationships (McNabb, 2015).

The research hypotheses below are developed based on the proposed research model that is under scrutiny. The research questions were presented earlier, based on the research objectives to identify the possible factors that significantly affect the use of e-wallets in the Kingdom of Bahrain, objectives were also presented in detail in the introduction.

Research hypotheses were derived based on the research questions, research objectives, and research proposed model that is under scrutiny. The following hypotheses are given with a brief explanation for each.

$\mathbf{H}_{\mathbf{1}}$ : The ease of use of e-wallet directly affects the participants' satisfaction concerning the use of e-wallet.

The individual who finds the use of e-wallet straightforward is more satisfied to use it.
This hypothesis assumes there is a significant direct effect of ease of use on the users' satisfaction. In other words, does ease of use of e-wallet has a significant direct role in determining the user level of satisfaction?

$\mathbf{H}_{2}$ : The ease of use of e-wallet indirectly affects the participants' continuance use through the satisfaction concerning the use of e-wallet, as being a financial mediator.

An individual who finds the use of e-wallet straightforward intends to continue using e-wallets only if they are satisfied with it. This hypothesis assumes there is a significant indirect effect of ease of use on the users' continuance use through users' satisfaction level as a mediator. In other words, does ease of use of e-wallet has a significant indirect role in determining the user continuance use through satisfaction as being a mediator?

$\mathbf{H}_{3}$ : The compatibility of using an e-wallet directly affects the participants' satisfaction concerning the use of e-wallet.

An individual who finds the use of e-wallet compatible and that it meets the new trends in lifestyle feels more satisfied. This hypothesis assumes there is a significant direct effect of compatibility on the users' satisfaction. In other words, does the compatibility of e-wallet have a significant direct role in determining the user level of satisfaction?

$\mathbf{H}_{4}$ : The compatibility of using an e-wallet indirectly affects the participants' continuance use through satisfaction concerning the use of e-wallet, as being a mediator.

An individual who finds the use of e-wallet compatible and and that it meets the new trends in lifestyle intends to continue using e-wallets only if they are satisfied with it. This hypothesis assumes there is a significant indirect effect of compatibility on the users' continuance use through users' satisfaction level as a mediator. In other words, does the compatibility of e-wallet have a significant indirect role in determining the user continuance use through satisfaction as being a mediator?

$\mathbf{H}_{5}$ : The usefulness of e-wallet directly affects the participants' satisfaction concerning the use of e-wallet.

An individual who finds e-wallet useful is more satisfied. This hypothesis assumes there 
is a significant direct effect of usefulness on the users' satisfaction. In other words, does the usefulness of e-wallet have a significant direct role in determining the user level of satisfaction?

$\mathbf{H}_{6}$ : The usefulness of e-wallet indirectly affects the participants' continuance use through satisfaction concerning the use of e-wallet, as being a mediator.

An individual who finds e-wallet useful intends to continue using e-wallets only if they are satisfied. This hypothesis assumes there is a significant indirect effect of usefulness on the users' continuance use through users' satisfaction level as a mediator. In other words, does the usefulness of e-wallet have a significant indirect role in determining the continuance use through satisfaction as being a mediator?

$\mathbf{H}_{7}$ : The security of e-wallet directly affects the participants' satisfaction concerning the use of e-wallet.

An individual who finds e-wallet secure and safe is more satisfied. This hypothesis assumes there is a significant direct effect of security on participant satisfaction. In other words, does the security of e-wallet have a significant direct role in determining the user level of satisfaction?

$\mathbf{H}_{\mathbf{8}}$ : The security of e-wallet indirectly affects the participants' continuance use through satisfaction concerning the use of e-wallet, as being a mediator.

An individual who finds e-wallet secure and safe intends to continue using e-wallets only if they are satisfied. This hypothesis assumes there is a significant indirect effect of security on the users' continuance use through users' satisfaction level as a mediator. In other words, does the security of e-wallet have a significant indirect role in determining the user continuance use through satisfaction as being a mediator?

$\mathbf{H}_{\mathbf{9}}$ : The participant's satisfaction of e-wallet directly affects the continuance use concerning the use of e-wallet.

The satisfied individual is anticipated to continue using the e-wallet. This hypothesis assumes there is a significant direct effect of users' satisfaction on the continuance use. In other words, does the level of satisfaction of e-wallet have a significant direct role in deciding the user continuance use of e-wallet?

$\mathbf{H}_{10}$ : The participants' demographic characteristics play a moderate role in the relationship between the satisfaction concerning the use of e-wallet and the four predictor variables (ease of use, compatibility, usefulness, and security).

\section{Operated and Conceptual, Definitions of the Variables}

The conceptual definition of variables was presented earlier; it was derived from the theoretical researches and defined in more abstract terms (Punch, 2003). In other words, the definition differs in how the researcher employs and measures the variables in the study from the view of conceptual definitions. Punch (2003) recognizes the survey as the process of moving from the conceptual level to the operational.

Table 2 below summarizes the conceptual and operational definitions of the variables used in this research.

Survey participants are defined as members of a sample drawn from all users of local e-wallets in Bahrain. Careful considerations were taken to guarantee the selection of the variety of participants' characteristics to include those of different gender, age, educational background, and employment status. The participants received an electronic questionnaire. The sample size calculation was determined based on Krejcie \& Morgan (1970). They set a rule of thumb, which stated that if the population is 1 million and above, the sample size shall be 384 participants based on confidence level 95\% (degree of accuracy). This rule was adopted for this study due to the unknown for the researcher population size. This study has managed to collect a sample size of 660 responses, which is considered quite a large sample size for any statistical analysis.

The study is focusing on the Kingdom of Bahrain to identify factors that affect the use and the continuance use of e-wallets. Therefore, the targeted population for this study are all e-wallets users in the Kingdom of Bahrain. Accordingly, the sampling for this study was 
Table 2. Operated Conceptual Definition of Variables

\begin{tabular}{|c|l|l|}
\hline Variables & \multicolumn{1}{|c|}{ Conceptual Definition } & \multicolumn{1}{|c|}{ Operational Definition } \\
\hline Ease of Use & $\begin{array}{l}\text { The level of easiness and user-friendliness in using e-wal- } \\
\text { lets, the volume of effort needed to perform transactions } \\
\text { (Chen \& Wu, 2017) }\end{array}$ & $\begin{array}{l}\text { Likert scale with five questions was } \\
\text { used to measure this variable }\end{array}$ \\
\hline Compatibility & $\begin{array}{l}\text { The degree of consistency of e-wallet with the users' life- - } \\
\text { styles and needs (Chen \& Wu, 2017) }\end{array}$ & $\begin{array}{l}\text { Likert scale with five questions was } \\
\text { used to measure this variable }\end{array}$ \\
\hline Usefulness & $\begin{array}{l}\text { The degree to which the e-wallets are useful and provide } \\
\text { benefits to help users facilitate particular activity (Ven- } \\
\text { katesh et al., 2012; Madan \& Yadav, 2016; Chen \& Wu, } \\
\text { 2017) }\end{array}$ & $\begin{array}{l}\text { Likert scale with four questions was } \\
\text { used to measure this variable }\end{array}$ \\
\hline Security & $\begin{array}{l}\text { The extent to which users believe that using an e-wallet } \\
\text { is secured. The security consists of authentication, con- } \\
\text { fidentiality, non-repudiation, and data integrity (Han, } \\
\text { 2003) }\end{array}$ & $\begin{array}{l}\text { Likert scale with three questions } \\
\text { was used to measure this variable }\end{array}$ \\
\hline Satisfaction & $\begin{array}{l}\text { The degree of positive feeling the users experience when } \\
\text { they use e-wallet (Chen \& Wu, 2017) }\end{array}$ & $\begin{array}{l}\text { Likert scale with four questions was } \\
\text { used to measure this variable }\end{array}$ \\
\hline $\begin{array}{l}\text { Continu- } \\
\text { ance Use }\end{array}$ & $\begin{array}{l}\text { Users desire to continuously use e-wallet (Cao et al., 2018) } \\
\text { used to measure this variable }\end{array}$ & $\begin{array}{l}\text { Likert scale with five questions was } \\
\text { used }\end{array}$ \\
\hline
\end{tabular}

confined to the inhabitants in Bahrain and the number of smartphone users who use e-wallets application.

\section{Targeted Population \\ and Sampling Techniques}

The targeted population is generally defined as the number of people living in a particular area (Taherdoost, 2016). On the one hand, the below Table 3 shows the targeted population in the Kingdom of Bahrain as obtained from The Information \& eGovernment Authority (IGA). The latest data, published in the middle of the year 2018, sorted by gender, age groups, and nationality.

As shown in the Table 3 above, the total population exceeds 1.5 million. However, the individuals belonging to the age group between 0 to 14 years are excluded from the population because it is comprised of children. This age group $(0-14)$ supposedly do not have a bank account. If they have a bank account, it is controlled by their parents or their custody, therefore we are unable to review their experience in using e-wallets application, and they are excluded from the e-wallet population. Accordingly, the e-wallet population shrinks to almost 1.2 million.
Generally, sampling techniques are divided into two types: probability (random) sampling and non-probability (non-random) sampling. Both types are used for selecting the required sample size (Taherdoost, 2016).

According to Taherdoost (2016), probability sampling indicates equal opportunities for each sampling unit in the entire population to be randomly selected as a study sample; it is considered time and energy-consuming. However, it is free from bias method, whereas the non-probability sampling is used for a smaller sample size concerning selection conditions and rules.

The probability sampling technique is based on the principle of randomization, wherein the procedure is so designed, which guarantees that each sampling unit of the population has an equally likely chance to be selected. This method will help to reduce the possibility of biasness (Rahi, 2017).

The non-probability sampling includes several types such as convenience, purposive or judgmental, and quota sampling. Based on the above explanation of each type of the non-probability sampling method, participants were selected through snowball (chain-referral) and convenience sampling technique. The 
Table 3. Bahrain Population

\begin{tabular}{|c|c|c|c|c|c|}
\hline \multirow{2}{*}{ Age group } & \multicolumn{2}{|c|}{ Bahraini } & \multicolumn{2}{c|}{ Non-Bahraini } & \multirow{2}{*}{ Total } \\
\cline { 4 - 5 } & Males & Females & Males & Females & \\
\cline { 1 - 1 } Below 14 & 110,199 & 105,556 & 41,242 & 39,891 & 296,888 \\
\cline { 1 - 1 } $15-19$ & 31,889 & 30,035 & 8,836 & 7,238 & 77,998 \\
\cline { 1 - 1 } $20-24$ & 30,591 & 28,932 & 37,636 & 15,380 & 112,539 \\
\cline { 1 - 1 } $25-34$ & 55,896 & 54,014 & 227,037 & 68,198 & 405,145 \\
\cline { 1 - 1 } $35-44$ & 43,354 & 42,779 & 169,733 & 49,466 & 305,332 \\
\cline { 1 - 1 } Above 45 & 77,732 & 78,737 & 112,719 & 36,001 & 305,189 \\
\cline { 1 - 1 } Total & 349,661 & 340,053 & 597,203 & 216,174 & $1,503,091$ \\
\hline
\end{tabular}

previous studies gave handy information on a similar sampling method, either one sampling technique or combination of sampling techniques. For example, Kumar et al. (2018) used a convenience sampling technique, while Madan \& Yadav (2016) used a combination of snowball (chain-referral), convenience, and judgmental sampling techniques.

There are several reasons for combining two types of non-probability sampling methods, which are convenience and snowball sampling. The convenience sampling technique was used because it provides members that are readily available and easy to approach, such as friends and family. This type of sampling technique is considered as inexpensive, the least time consuming, and most convenient method.

The snowball (chain-referral) sampling technique was used also due to several reasons. Firstly, due to difficulties in framing the sampling because of the inability to reach the targeted population list from the concerned authorities. The data had a sensitive and close nature. Secondly, the sample members do not come together, and it is challenging to locate users. Third, there is no other way to access the sample because of failure in determining the sample representatives, so the first selected members of the sample would refer to other members.

\section{Questionnaire Design}

The voluntary participants have been requested to fill-out a well-designed questionnaire divided into three sections. The first section had general information about the usage of e-wallet and consisted of 6 questions. The second section of the questionnaire contained 26 multiple statements of a 5-point Likert scale. This section was built to assess user satisfaction by indicating the level of agreeing or disagreeing on four factors (variables) that have an impact on the continuance use of e-wallets. The indication of number " 1 " means strongly disagreement while strongly agreement is reflected by number " 5 ". The final section was related to demographical background and consisted of 4 questions related to gender, age, and education.

The questionnaire was written in both languages, Arabic and English. The reason for introducing the Arabic version was to make sure that all people with different educational backgrounds could participate in this study.

The first questionnaire's pilot testing was conducted on 22 respondents, the questionnaire was initially sent through a mobile application to friends and family members. After three trials, the questionnaire was amended according to the respondents' feedback and results. However, the questionnaire was then uploaded using Survey Monkey. Moreover, there was an amendment regarding wording translation in Arabic.

The process involved distributing the self-administered questionnaire using an exponential non-discriminative snowball and convenience sampling technique. The convenience sampling technique was used first because it comprised of members that were readily available and easy to approach, such as friends and family. The convenience method could connect 
family, friends, and any volunteer through social media applications to fill the online survey (electronic form using Survey Monkey website). Also, we could ask the respondents to forward the survey to their connections who use the e-wallets, which led us to employ exponential non-discriminative snowball sampling technique.

It was helpful to use social networks in distributing the questionnaire to collect a large number of responses. Consideration was given to the inclusion of age, gender, education factors to show the trends by diversity. The message contains information about the usage of the survey as it was intended for study purposes only, ensuring protection of the personal data of participants, and they had the right to be withdrawn from the research's sample at any time if requested. Additionally, upon the participant's request, a copy of the final research study was provided.

\section{Analysis and Findings}

Reliability was defined roughly as the precision of scale scores; it means the degree to which scores accurately reflect some actual state of the variable in a given sample (Furr, 2011). The need to check the scale reliability is to ensure that the instrument produces an accurate and consistent measurement. A reliable instrument is an instrument that works consistently and predictably (DeVellis, 2016).

If the scale is reliable, that means it represents the actual state of the variable being evaluated. In practice, the score produced remains stable unless any change occurs in the actual variable the instrument is evaluating (DeVellis, 2016).

The most popular measurement of internal consistency is Cronbach Alpha, which varies between 0 and 1. Cronbach Alpha is an "item-level" internal consistency approach, using inter-item associations to estimate the reliability of scale scores (DeVellis, 2016), it describes to what extent all items in the test measure the construct.

The Cronbach Alpha was used in this study to measure the reliability of the instrument used. If the score of Cronbach Alpha is 0.7 and more, then it would indicate the reliability of high internal consistency, which means that the reliability of scale has been achieved (Pontes et al., 2014).

The study comprises six scales (variables), of which all showed an excellent reliability index on Cronbach's Alpha except for the "Usefulness" scale, which was suboptimal (as it was below 0.7). All items in these scales contributed well to their scales' overall reliability as the Corrected Total-Item correlation ranged between 0.32 and 0.67 . The following tables show more details about Cronbach's Alpha for the dependent and independents variables.

\subsection{Structural Equation Modeling Analysis}

Structural Equation Modeling (SEM) is a multivariate statistical analysis technique that is used to analyze structural relationships. This technique is a combination of factor analysis and multiple regression analysis. It is commonly used to analyze the structural relationship between measured variables and latent constructs (Hair et al., 2016). Latent constructs are the variables that are neither directly observed nor measured (Byrne, 2013).

The observed variables are measured during the data collection process, and latent variables are the variables measured by connecting to the observed variables as they cannot be measured directly.

The most important reason for the spread of this statistical technique (SEM) is the ability to quantify both the direct and indirect relationships between the variables and latent constructs within one model (Civelek, 2018). Another reason for the widespread of this statistical technique (SEM) is the ability to take into account the measurement errors and the relationships between errors in the observed variables with the minimization of the measurement errors. In traditional regression analysis, potential measurement errors are neglected (Civelek, 2018).

However, to understand relationships in a complex model that contains many path relationships and consists of latent variables and constructs, it is necessary to employ sophisticated multivariate analysis such as Structural Equation Modeling (Hair et al., 2016). 


\subsection{Direct constructs relationships}

Figure 4 below shows the proposed model structure based on the partial least square structural equation modeling. All the hypothesized relationships were estimated and turned to be statistically significant as the p-value of each factor is less than 0.05 . Among the four factors, the weakest relationship identified between usefulness and satisfaction is the beta equals +0.091 . Collectively, ease of use, compatibility, usefulness, and security exert a considerable effect on satisfaction as reflected by a sizeable adjusted $\mathrm{R}^{2}=0.642$.

The most significant effect on the participants' satisfaction with the use of e-wallets came mainly from security (beta $=+0.337$, $\mathrm{p}<0.0001$ ) and ease of use (beta $=+0.336$, $\mathrm{p}<0.0001)$. The following Table 4 shows the direct effects flowing in the model:

\subsection{Demographic variables}

The four factors are grouped in one indicator in order to test whether the relationship is strengthening in case of introducing the demographic variables between the factors and user satisfaction. As shown in Fig. 5 and Table 5 below, the moderating variables are statistically insignificant as the p-value is above 0.05 .

\subsection{Indirect constructs relationships}

As being proposed in the model, satisfaction has a relationship with continuance which turned to be powerful and statistically significant (beta $=+0.791,=0.626, p<0.0001$ ), as shown in Fig. 4. However, the four stated factors do have indirect effects on continuance via the mediating variable "satisfaction." The largest observed indirect effects were exerted by ease of use (beta $=0.266, p<0.0001)$ and securi-

Table 4. Direct constructs relationships

\begin{tabular}{|c|lc|c|}
\hline $\begin{array}{c}\text { Path of a direct } \\
\text { relationship }\end{array}$ & \multicolumn{1}{|c|}{ Beta* } & \multicolumn{1}{c|}{ p-value } \\
\hline Compatibility & Satisfaction & +0.206 & $<0.0001$ \\
\hline Ease of use & Satisfaction & +0.336 & $<0.0001$ \\
\hline Security & Satisfaction & +0.337 & $<0.0001$ \\
\hline Usefulness & Satisfaction & +0.091 & 0.025 \\
\hline Satisfaction & \multicolumn{1}{|c|}{ Continuance +0.791} & $<0.0001$ \\
\hline
\end{tabular}

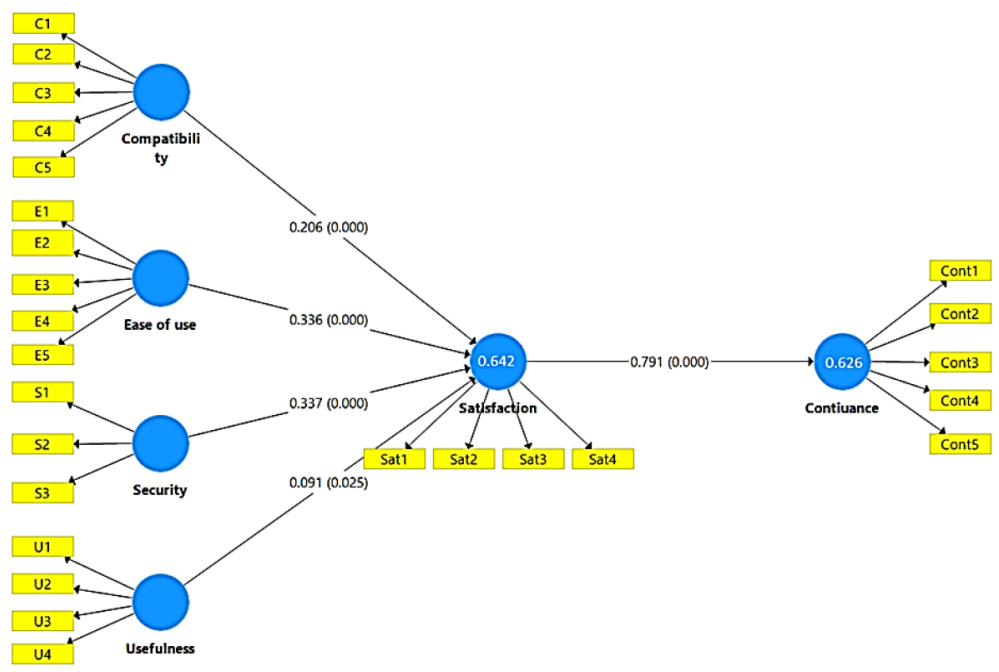

Fig. 4. Direct Construct Relationships 
Table 5. Demographic variables

\begin{tabular}{|l|c|c|}
\hline \multicolumn{1}{|c|}{ Path of a direct relationship } & Beta* & p-value \\
\hline Age moderating effect Four predictors/Satisfaction & -0.057 & 0.149 \\
\hline Gender moderating effect Four predictors/Satisfaction & +0.024 & 0.510 \\
\hline Education moderating effect Four predictors/Satisfaction & -0.022 & 0.326 \\
\hline Employment moderating effect Four predictors/Satisfaction & +0.036 & 0.326 \\
\hline
\end{tabular}

* Based on T statistic.

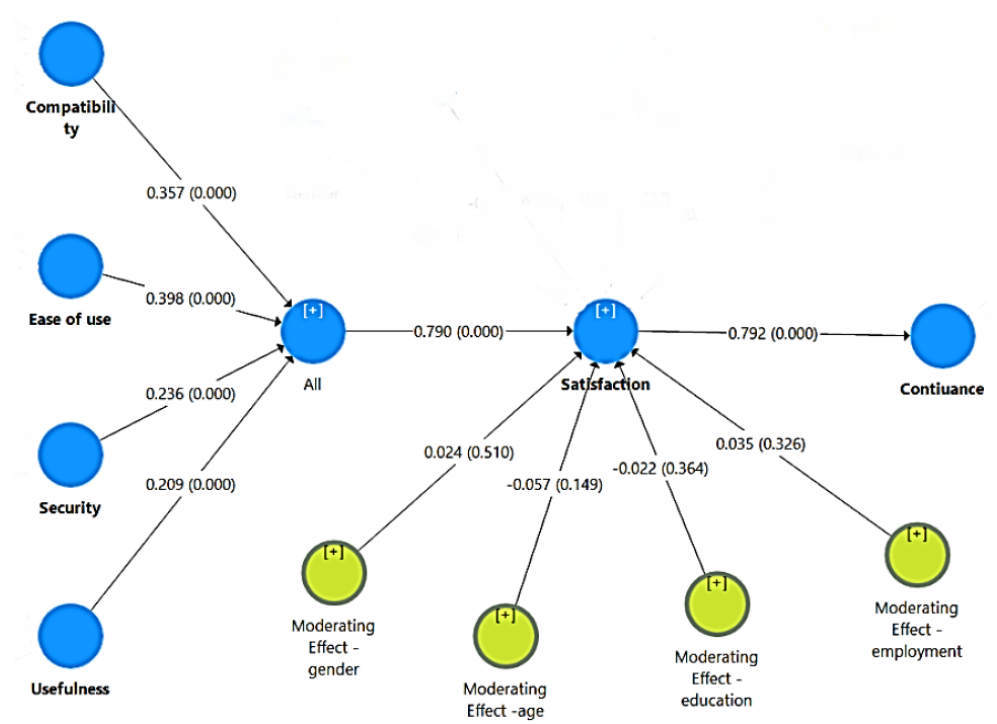

Fig. 5. Demographic Variables

Table 6. Indirect constructs relationships

\begin{tabular}{|c|c|c|}
\hline Path of indirect relationship & Indirect Beta* & p-value \\
\hline Compatibility $\rightarrow$ Continuance & $0.163\left(0.206^{*} 0.791\right)$ & $<0.0001$ \\
\hline Ease of use $\rightarrow$ Continuance & $0.266\left(0.336^{*} 0.791\right)$ & $<0.0001$ \\
\hline Security $\rightarrow$ Continuance & $0.267\left(0.337^{*} 0.791\right)$ & $<0.0001$ \\
\hline Usefulness $\rightarrow$ Continuance & $0.072\left(0.091^{*} 0.791\right)$ & $<0.0001$ \\
\hline
\end{tabular}

*The indirect effect is the product of multiplying the direct effect between the factor and the mediator (satisfaction) and the direct effect between the mediator and the dependent variable (continuance) - based on T statistic.

ty (beta $=0.267, p<0.0001)$. The following Table 6 delineates the magnitude of the four factors' indirect effects on continuance:

In summary, the above hypotheses were tested and it was concluded that all hypotheses were accepted except the moderating variables hypotheses. The below Table 7 shows in detail:

\subsection{The saturated model}

The Fig. 6 below shows the saturated model based on the partial least square structural equation modelling that outlines all possible relationships that may exist between the construct variables. On the one hand, the ease of use (beta $=-0.079, p=0.082$ ) and security 
Table 7. Hypothesis summary

\begin{tabular}{|l|l|}
\hline \multicolumn{1}{|c|}{ Hypothesis } & \multicolumn{1}{|c|}{ Findings } \\
\hline$H_{1}:$ Ease of use $\rightarrow$ Satisfaction & Supported (significant) \\
\hline$H_{2}:$ Ease of use $\rightarrow$ Satisfaction $\rightarrow$ Continuance & Supported (significant) \\
\hline$H_{3}:$ Compatibility $\rightarrow$ Satisfaction & Supported (significant) \\
\hline$H_{4}:$ Compatibility $\rightarrow$ Satisfaction $\rightarrow$ Continuance & Supported (significant) \\
\hline$H_{5}:$ Usefulness $\rightarrow$ Satisfaction & Supported (significant) \\
\hline$H_{6}:$ Usefulness $\rightarrow$ Satisfaction $\rightarrow$ Continuance & Supported (significant) \\
\hline$H_{7}:$ Security $\rightarrow$ Satisfaction & Supported (significant) \\
\hline$H_{8}:$ Security $\rightarrow$ Satisfaction $\rightarrow$ Continuance & Supported (significant) \\
\hline$H_{9}:$ Satisfaction $\rightarrow$ Continuance & Supported (significant) \\
\hline$H_{10.1}:$ Age moderation $\rightarrow$ Four predictors - Satisfaction & Unsupported (insignificant) \\
\hline$H_{10.2}:$ Gender moderation $\rightarrow$ Four predictors - Satisfaction & Unsupported (insignificant) \\
\hline$H_{10.3}:$ Education moderation $\rightarrow$ Four predictors - Satisfaction & Unsupported (insignificant) \\
\hline$H_{10.4}:$ Employment moderation $\rightarrow$ Four predictors - Satisfaction & Unsupported (insignificant) \\
\hline
\end{tabular}

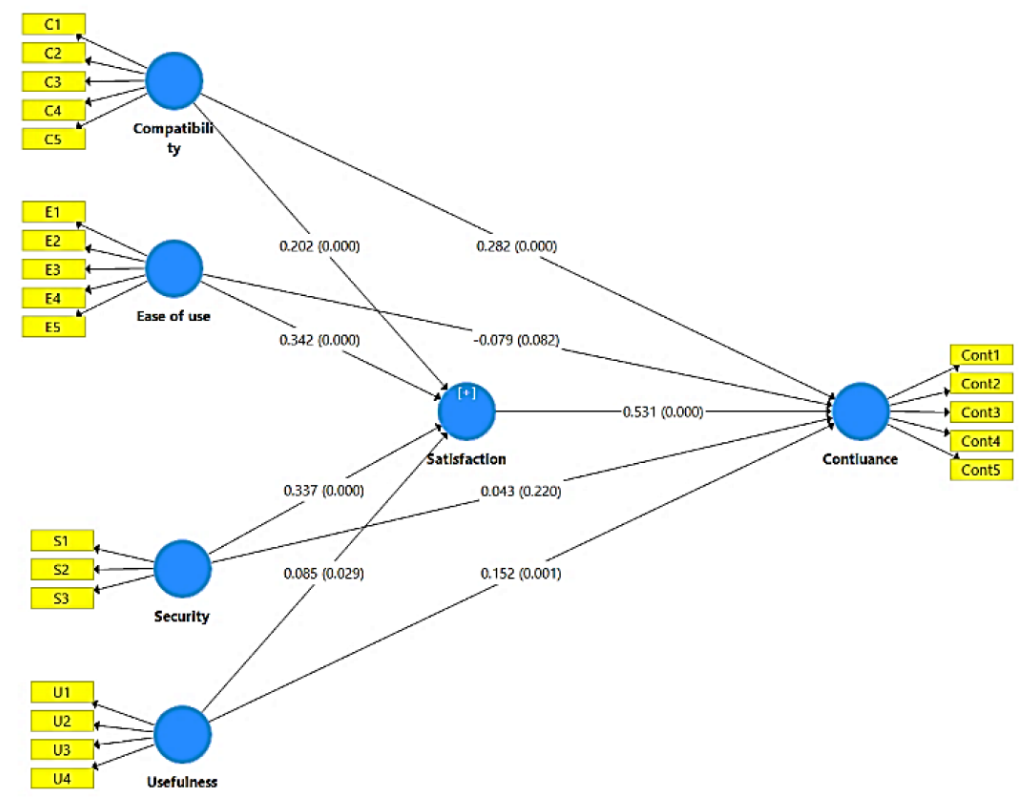

Fig. 6. The Saturated Model

(beta $=0.043, p=0.220$ ) are recognized as statistically insignificant relationships with the continuance use. On the other hand, compatibility (beta $=+0.282, \mathrm{p}<0.0001)$ and usefulness (beta $=+0.152, \mathrm{p}=0.001$ ) are recognized as statistically significant relationships with the continuance use.

\subsection{The corrected model}

The Fig. (7) below shows the corrected model structure based on the partial least square structural equation modelling that outlines the statistically significant relationships that exist between the construct variables. 
As shown above, in Fig. 6, the model is corrected to include the direct path of the statistically significant relationships that are proved in this study. The new adjusted is 0.699 while previously adjusted was 0.626 in the proposed model, since adjusted has the ability to quantify the percentage of explanation in the continuance use by the four factors in the model [ease of use, compatibility, security, usefulness]. Therefore it is a good indicator to determine the optimal model. This noticeable improvement in adjusted $\mathrm{R}^{2}$ means that almost $70 \%$ of continuance use is well predicted by the four factors, which means it is an instrumental model. The ease of use, compatibility, usefulness, and security exert an enormous effect on continuance use as reflected by a sizeable adjusted $\mathrm{R}^{2}=0.699$. The total effect on the continuance use is shown in the Table 8 below.

\section{Discussion}

The principal target of this research is to find how statistically significant the proposed factors (that might impact the e-wallet usage and its continuance use in Bahrain) are. The collected sample consists of 660 participants for this research. The respondents answered the survey of 36 close-ended questions in total. The analyzed data have shown the following demographic characteristics:

- Males formed the majority of participants, with $61.4 \%$.

Table 8. Beta Coefficients

\begin{tabular}{|c|c|c|c|}
\hline Relationship & Indirect Beta* & Direct Beta & Total Beta** \\
\hline Compatibility $\rightarrow$ Continuance & $0.105\left(0.202^{*} 0.520\right)$ & 0.267 & 0.372 \\
\hline Ease of use $\rightarrow$ Continuance & $0.178(0.342 * 0.520)$ & - & 0.178 \\
\hline Security $\rightarrow$ Continuance & $0.177(0.340 * 0.520)$ & - & 0.177 \\
\hline Usefulness $\rightarrow$ Continuance & $0.044\left(0.084^{*} 0.520\right)$ & 0.147 & 0.191 \\
\hline
\end{tabular}

*The indirect effect is the product of multiplying the direct effect between the factor and the mediator (satisfaction) and the direct effect between the mediator and the dependent variable (continuance).

***The total Beta is the sum of indirect beta and direct beta.

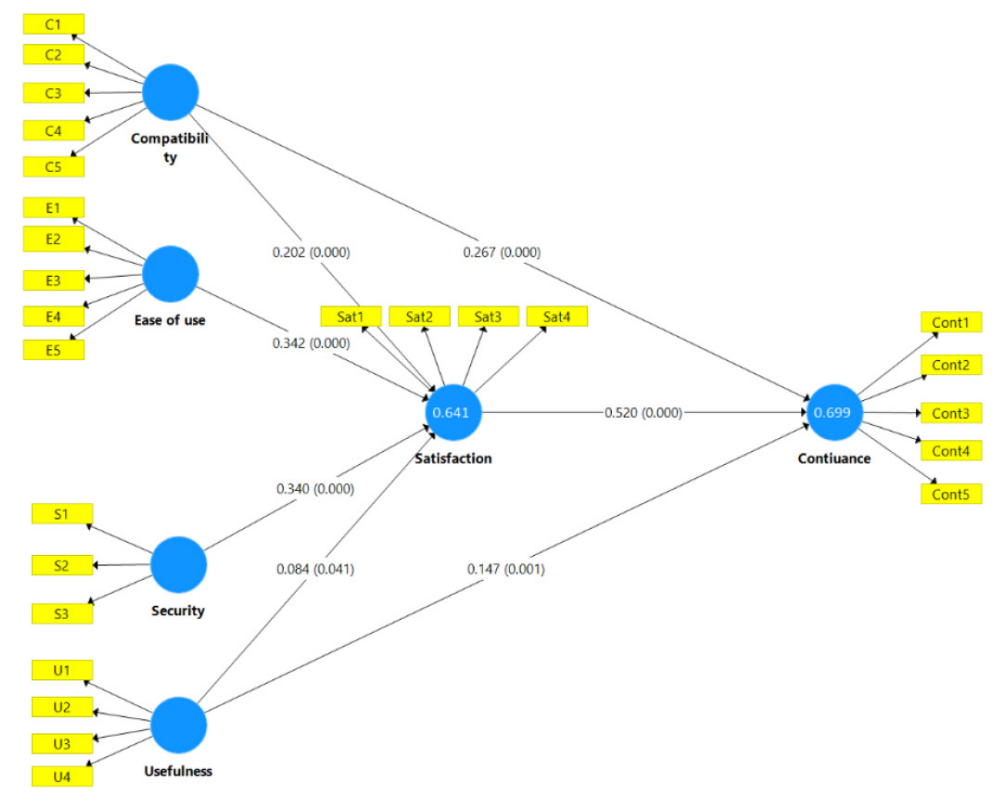

Fig. 7. The Corrected Model 
- Participants aged between 26 and 35 years amounted to more than half of the sample $(52.4 \%)$.

- The vast majority of participants hold Bachelor's and higher academic degrees (76.3\%).

- Participants aged between 26 and 35 years, who hold a Bachelor's degree, formed a third of the sample.

- Three-quarters of the participants are employed (75.2\%).

The relationships proved in this research to be significant between the satisfaction of e-wallet use and the four predictor variables [ease of use, compatibility, usefulness, and security], this is consistent with studies conducted earlier (Chen \& Wu, 2017; Kumar et al., 2018; Bagla \& Sancheti, 2018; Singh et al., 2017; Madan \& Yadav, 2016).

Moreover, the result of the demographic characteristics did not show a significant moderating relationship between the satisfaction of using e-wallet and any of the four predictor variables. It means that an individual's gender, age, qualification, and employment status would not affect the satisfaction level in terms of ease of use, compatibility, usefulness, and security (independent variables). This finding is consistent with Avornyo et al. (2019) who found that gender, education, and occupation have an insignificant effect on continuous use. Also, Cao et al. (2018) found that age has insignificant effects on the continuance of intentional use.

The results are discussed with the comparison of previous literature findings and interpreted to satisfy the research questions and hypotheses in the following sections.

This research aimed to identify the main factors that have a significant impact on the e-wallet usage and its continuance use. The study successfully merged the elements of the Technology Acceptance Model (TAM) and Expectancy-Confirmation Model (ECM). Also, this study successfully extended the research model to include two new predictor variables that were previously examined (Chen \& Wu, 2017; Kumar et al., 2018; Bagla \& Sancheti, 2018). Furthermore, the study introduced the moderating effect of the demographic charac- teristics on the relationship between satisfaction of using e-wallet and the four variables that were previously examined (Cao et al., 2018; Singh et al., 2017; Yang et al., 2014; Zheng et al., 2013).

This study results indicated that all direct relationships between the satisfaction of e-wallet and the four predictor variables (ease of use, compatibility, usefulness, and security) are significant. Also, the direct relationship between continuance use and satisfaction of using e-wallet is statistically significant and supported (Albashrawi \& Motiwalla, 2019; Tam et al., 2018; Cao et al., 2018; Kumar, 2018; Chen \& Wu, 2017; Singh, 2017; Hsiao et al., 2016). This means that the relationships are statistically significant between satisfaction concerning the use of e-wallet and the four predictors (ease of use with a $p$-value of $<0.0001$, compatibility with a p-value of $<0.0001$, usefulness with a $\mathrm{p}$-value of 0.025 , and security with a $\mathrm{p}$-value of $<0.0001$ ). The analysis showed a significant relationship between continuance usage and satisfaction concerning the use of e-wallet with a $p$-value of $<0.0001$.

Furthermore, this study results indicated that all indirect relationships between continuance use and the four predictor variables [ease of use, compatibility, usefulness, and security] are statistically significant and supported (Albashrawi \& Motiwalla, 2019; Jusuf et al., 2017; Chen \& Li, 2017; Yuan et al., 2016; Hamid et al., 2016). This means that the relationships are statistically significant between continuance and the four predictors (ease of use ( $\mathrm{p}$-value $<0.0001$ ), compatibility ( $p$-value $<0.0001$ ), usefulness ( $\mathrm{p}$-value $<0.0001$ ) and security ( $\mathrm{p}$-value $<0.0001)$ ).

The moderating variables were found to be statistically insignificant (Avornyo et al., 2019; Cao et al., 2018). The analysis showed that the moderating variables of gender, age, qualification, and employment status are not significant concerning the use of the e-wallet variable. Its significance level was as follows respectively: $0.351,0.149,0.326,0.326$.

This study is consistent with previous studies (Chen \& Wu, 2017; Singh et al., 2017) that found that the ease of use of e-wallets affects directly user satisfaction concerning the 
use of e-wallet. The use of e-wallet to perform transactions was founded to be much easier and faster compared to the traditional method as e-wallet shortens the process of conducting the transactions (Madan \& Yadav, 2016).

The research of Chen \& Wu (2017) indicates that the "usefulness variable" of mobile payments directly affects user satisfaction, while the compatibility of mobile payment results indirectly in satisfaction through usefulness and ease of use. However, both "compatibility" and "usefulness" variables are found in this study significant predictors that directly affect user satisfaction. Once users are satisfied with the promotional benefits of e-wallet, they will increase the usage of e-wallet (Singh et al., 2017).

However, this study is consistent with the earlier study of Chen \& Wu (2017) that substantiated that the more secure the users feel about the technology, the higher the satisfaction.

There are also several studies (Wessels \& Drennan, 2010; Singh et al. 2017; Riquelme \& Rios, 2010) that consider the demographic characteristics as significant variables in determining the satisfaction level of the e-wallet usage. However, in these studies the demographic variables have no significant effects on the relationships that exist between the satisfaction and the four predictors (ease of use, compatibility, usefulness, and security).

This study presents a proposed research model that is under scrutiny. Still, in an attempt to discover all possible relationships that may exist between the construct variables, the saturated model was introduced. The saturated model outlines the comprehensive relationships that may exist in the entire model. The findings of the saturated model will be discussed below.

First, the adjusted $\mathrm{R}^{2}$ value is considered as a valuable indicator of the goodness of any mathematical model; the higher the value of the adjusted $\mathrm{R}^{2}$, the better. The adjusted $\mathrm{R}^{2}$ was 0.626 in the model that is under the scrutiny of this study, the proposed model. Nevertheless, in the saturated model, the model that outlines all possible relationships that may exist in the model, the new, improved adjusted $\mathrm{R}^{2}$ value is 0.699 .

The ease of use, compatibility, usefulness, and security variables exert a substantial effect on continuance use, as reflected by a sizeable adjusted $R^{2}=0.699$. Since the adjusted $R^{2}$ can quantify the percentage of explanation in the continuance use by the four factors in the model (ease of use, compatibility, security, usefulness), it is a good indicator to select the better model.

The noticeable improvement in adjusted $\mathrm{R}^{2}$ means that the four factors efficiently predict almost $70 \%$ of continuance use; therefore, it means we have obtained a better model.

Second, two of the model factors have a direct relationship with continuance use, while two of the factors have no direct relationship with continuance use.

The compatibility and usefulness variables are recognized as significant direct relationships with the continuance use. The direct relationship between usefulness and the continuance use is consistent with the ECM model and Chen \& Li, (2017) findings. This means that if an individual finds the e-wallet is useful and compatible with their needs and wishes, they will continue using it even if they are not satisfied.

Nonetheless, the ease of use and security variables have shown insignificant direct relationships with the continuance use variable (Avornyo et al., 2019). This means that if an individual continues to use an e-wallet, then he/she should be satisfied concerning ease of use and security of e-wallet. If the individual is unsatisfied with the e-wallet ease of use and unsatisfied with the e-wallet security, they will not continue using it.

Third, as an indication of the leading factor that affects the use and the continuance use, the comparison is made by identifying the highest number of total Beta figures. Among the four predictors (ease of use, compatibility, usefulness, and security), the results indicate that the compatibility is the leading factor that exerts the highest effect on continuance use, as reflected by the total Beta $=0.372$ as shown in table (4.27).

\section{Research Conclusions and Limitations}

This research intended to identify factors that affect the use of e-wallets. This study combined the TAM and ECM models in order to 
understand the reasons for the use of e-wallet and continuous use.

The empirical results of this study demonstrated that direct relations are statistically significant between satisfaction concerning the e-wallet use, and the four predictors (ease of use, compatibility, usefulness, and security). Also, the relation between continuance usage and satisfaction concerning e-wallet use is statistically significant.

Moreover, the results show that continuance usage is indirectly and considerably influenced by the four predictors (ease of use, compatibility, usefulness, and security). However, the moderating variables were found to be statistically insignificant (demographic variables) in the relationship between the satisfaction and the four predictors (ease of use, compatibility, usefulness, and security).

This research analysis is classified as an inferential statistics analysis exercise conducted to discover the factors that affect the use of e-wallet in the Kingdom of Bahrain. Data was collected through an online questionnaire. This study managed to collect 660 completed responses that gave a much more excellent opportunity to draw a more accurate conclusion and reflect the real position of factors that gauge the e-wallet usage. However, this study has experienced many limitations. First, the study was limited to the users in the Kingdom of Bahrain with relatively small sample size. The source of satisfaction may differ among countries (Zhang et al., 2012); therefore, the identified factors that affect the individual satisfaction and usage of e-wallet may differ from country to country. Thus, the study results cannot be generalized outside Bahrain.

Second, this research was designed to identify the significance of four factors only. However, there may be other important factors, such as the social influence on the e-wallets usage that were not investigated due to the time limitation of the study. Third, the lack of previous researches poses a challenge in selecting the optimal theoretical model to investigate the driven factors towards the new concept of us- ing e-wallets. However, the selected two models to this study were TAM and ECM models that were used by the previous research work in investigating new technology.

Forth, the lack of direct interaction with the participants poses limitations as the data collected using a self-administered survey. The study conducted a pilot study to gauge the level of respondent's understanding. The outcome of this pilot study showed adequate understanding and clarity of the survey's questions. Nevertheless, the researcher cannot verify the level of actual understandability of all participants in case of ambiguities. Fifth, this study identified the factors that affect the use of e-wallet in Bahrain regardless of the e-wallet providers. The data collected were analyzed and generalized with all e-wallet providers in Bahrain. In other words, individuals may be satisfied with regards to the security of specific e-wallet while not satisfied with other e-wallet providers. Future studies may be conducted to identify the variances among e-wallet providers.

\section{Recommendations for Future Research}

Finally, there are several highlighted points to be taken into consideration for future researches. The identified factors that affect the individual satisfaction and usage of e-wallet may differ from one country to another. Therefore, the satisfaction construct needs to be further investigated to obtain the significant factors that affect the use of e-wallet, enhancing the understandability of e-wallet usage. Moreover, the theoretical implications of this study are recommended to further expand in future research in order to validate the study results.

This study aggregates the results and recommendations of all involved factors among all e-wallet providers in Bahrain. These recommendations can be used to become basis for future researches and to analyze the factors that affect the use of each e-wallet provider separately, to provide a meaningful comparison on the strengths of each provider, as the strength of a specific provider may be a weakness for other providers. 


\section{References}

Akturan, U., \& Tezcan, N. (2012). Mobile banking adoption of the youth market: Perceptions \& intentions. In Marketing Intelligence \& Planning, 30(4), 444-459.]

Alaeddin, O., Rana, A., Zainudin, Z., \& Kamarudin, F. (2018). From physical to digital: Investigating consumer behavior of switching to a mobile wallet. In Polish Journal of Management Studies, 17.

Albashrawi, M., \& Motiwalla, L. (2019). Privacy \& Personalization in Continued Usage Intention of Mobile Banking: An Integrative Perspective. In Information Systems Frontiers, 1-13.

Amin, H., Supinah, R., Aris, M. M., \& Baba, R. (2012). The receptiveness of mobile banking by Malaysian local customers in Sabah: An empirical investigation. In Journal of Internet Banking \& Commerce, 15 (1), 1-11.

Avornyo, P., Fang, J., Odai, R.O., Vondee, J.B., \& Nartey, M.N. (2019). Factors Affecting Continuous Usage Intention of Mobile Banking in Tema and Kumasi. In International Journal of Business and Social Science, 10(3).']

Bagla, R. K., \& Sancheti, V. (2018). Gaps in customer satisfaction with digital wallets: a challenge for sustainability. In Journal of Management Development, 37(6), 442-451.

Benefit, (2017). THE BENEFIT COMPANY introduces the National E-Wallet by the 4th of July 2017, available at: https:/www.benefit.bh/events/2017/NationalEWallet.aspx?monthNo=6

Bhattacherjee, A (2001a). Understanding information systems continuance - An expectation-confirmation model. In MIS Quarterly, 25(3): 351-370.

Bhattacherjee, A. (2001b). An empirical analysis of the antecedents of electronic commerce service continuance. In Decision Support Systems, 32 (2), 201-214.

Boakye, K.G., Prybutok, V.R., \& Ryan, S.D. (2012).The intention of the continued web-enabled phone service usage: A quality perspective. In Operations Management Research, 5(1-2), 14-24.

Byrne, B.M. (2013). Structural equation modeling with Mplus: Basic concepts, applications, \& programming. Routledge.

Cao, X., Yu, L., Liu, Z., Gong, M., \& Adeel, L. (2018). Understanding mobile payment users' continuance intention: a trust transfer perspective. In Internet Research, 28(2), 456-476.

CBB (2019). Financial Stability Report, available at: https://www.cbb.gov.bh/ar/publications/

Chen, X. and Li, S. (2017). Understanding continuance intention of mobile payment services: an empirical study. In Journal of Computer Information Systems, 57, 4, 287-298

Chen, L.Y., \& Wu, W.N. (2017). An exploration of the factors affecting users' satisfaction with mobile payments. In International Journal of Computer Science and Information Technology (IJCSIT), 9, 3, June 2017

Chou, C.H., Chiu, C.H., Ho, C.Y., \& Lee, J.C. (2013). Understanding Mobile Apps Continuance Usage Behavior and Habit: An Expectance-Confirmation Theory. In PACIS, p. 132.

Civelek, M.E. (2018). Comparison of covariance-based and partial least square structural equation modeling methods under non-normal distribution and small sample size limitations. In Eurasian Academy of Sciences Eurasian Econometrics, Statistics \& Empirical Economics Journal, 10, 39-50.]

Creswell, J.W. (2013). Research design: Qualitative, quantitative, and mixed methods approach. Sage publications.

DeVellis, R.F. (2016). Scale development: Theory and applications (Vol. 26). Sage publications.'

Dimitrii, V. (2018). Determining factors of adoption of digital device wallets by Russian consumers. Thesis. St. Petersburg University.

Farah, M., Hasni, M.J. \& Abbas, A. (2018). Mobile banking adoption: empirical evidence from the banking sector in Pakistan. In International Journal of Bank Marketing, 36(7), 1386-1413.

Furr, M. (2011). Scale construction and psychometrics for social \& personality psychology. Sage Publications.

Garrett, J.L., Rodermund, R., Anderson, N., Berkowitz, S., \& Robb, C.A. (2014). Adoption of mobile payment technology by consumers. In Journal of Family and Consumer Sciences Research, 42(4), 358-368. 
Hair, Jr, J. F., Sarstedt, M., Hopkins, L., \& G. Kuppelwieser, V. (2014). Partial least squares structural equation modeling. In European Business Review, 26(2), 106-121.'

Hong, S. J., Thong, J. Y. L. \& Tam, K. Y. (2006). Understanding continued information technology usage behavior. In Journal of Decision Support Systems, 42(3), 1819-1834.

Hsiao, C.-H., Chang, J.-J., and Tang, K.-Y. (2016). Exploring the influential factors in continuance usage of mobile social Apps: Satisfaction, habit, and customer value perspectives. In Journal of Telematics and Informatics, 33 (2), 342-355. DOI:10.1016/j.tele.2015.08.014

Krejcie, R.V., \& Morgan, D.W. (1970). Determining sample size for research activities. In Educational and psychological measurement, 30(3), 607-610.

Kumar, A., Adlakaha, A., \& Mukherjee, K. (2018). The effect of perceived security \& grievance redressal on continuance intention to use M-wallets in a developing country. In International Journal of Bank Marketing, 36(7), 1170-1189.

Kwateng, K.O., Atiemo, K.A.O., \& Appiah, C. (2019). Acceptance \& use of mobile banking: an application of UTAUT2. In Journal of Enterprise Information Management.'

Madan, K., \& Yadav, R. (2016). Behavioral intention to adopt mobile wallets: a developing country perspective. In Journal of Indian Business Research, 8(3), 227-244.

Manikandan, M., \& Chandramohan, S. (2016). A study on the awareness level of mobile wallet services among management students. In International Journal of Advanced Research in Management \& Social Sciences, 5(7), 10-19.

McNabb, D.E. (2015). Research methods for political science: Quantitative \& qualitative methods. Routledge.']

Oliver, R.L. (1980). A cognitive model for the antecedents and consequences of satisfaction. In Journal of Marketing Research, 17(4), 460-469.

Pontes, H.M., Patrão, I.M., \& Griffiths, M.D. (2014). Portuguese Validation of the Internet Addiction Test- An Empirical Study. In The Journal of Behavioral Addictions, 3(2), 107-114.

Rahi, S. (2017). Research Design and Methods- A Systematic Review of Research Paradigms, Sampling Issues, and Instruments Development. In International Journal of Economics \& Management Sciences, 6(2), 1-5.

Singh, N., Srivastava, S., \& Sinha, N. (2017). Consumer preference \& satisfaction of M-wallets: a study on North Indian consumers. In International Journal of Bank Marketing, 35(6), 944-965.

Statistic, (2016). Total revenue of the global mobile payment market from 2015 to 2019 (in billion U.S. dollars). Available at: https:/www.statista.com/statistics/226530/mobile-payment-transaction-volue-forecast/

STC (2019). VIVA Cash launch, available at: https://www.stc.com.bh/content/cash_launch

Swilley, E. (2010). Technology rejection: the case of the wallet phone. In The Journal of Consumer Marketing, 27(4), 304-312.'

Taherdoost, H. (2016). What Is the Best Response Scale for Survey and Questionnaire Design; Review of Different Lengths of Rating Scale / Attitude Scale / Likert Scale HAL Id: Hal-02557308 Available at: https://hal.archives-ouvertes.fr/hal-02557308 Submitted on 6 May 2020

Carlos Tam, Diogo Santos \& Tiago Oliveira (2018). In Exploring the influential factors of continuance intention to use mobile Apps- Extending the expectation confirmation model. In Journal of Information Systems Frontiers, 1-15.

Venkatesh, Xu, \& Thong (2012). Consumer acceptance and use of information technology: extending the unified theory of acceptance and use of technology. In The MIS Quarterly, 157-178.

Webster, K., 2018. Mobile Wallets: Where is The S-Curve? Available at: PMTNS.com: https://www. pymnts.com/news/payments-innovation/2018/apple-pay-walmart-pay-samsung-pay-android-pay-mobilewallet-adoption-usage/

Yuan, S., Liu, Y., Liu, J. \& Yao, R. (2016). An investigation of user's continuance intention towards mobile banking in China. In Journal of Information Development, 32(1), 20-34.)

Zhang, L., Liu, Q., Zhu, J. (2012) A meta-analysis of mobile commerce adoption and the moderating effect of culture. In Computers in Human Behavior, 28, 1902-1911. 


\title{
Количественный подход к определению факторов, влияющих на использование электронных кошельков в Бахрейне
}

\author{
Мувафак М. Аль-Кубаиси, Недаа Насер \\ Университет Бахрейна \\ Бахрейн, Южная мухафаза, Сахир
}

\begin{abstract}
Аннотация. Бахрейн считается региональным лидером как в банковском, так и в финансовом секторе. Электронный кошелек, запущенный в 2017 году, - один из наиболее успешных инновационных сервисов. Этап определения факторов первичного внедрения новой технологии значимый, но недостаточный, так как компания - поставщик технологий должна выявить то, что влияет на использование электронного кошелька и его техническую поддержку, чтобы поддерживать пользователя в долгосрочной перспективе. В данном исследовании был использован количественный опросный подход, основанный на 5-балльной шкале Лайкерта. Анализ проведен методиками «снежный ком» и «случайная выборка», последняя состояла из 660 пользователей электронных кошельков в Бахрейне. Для обработки собранных данных применялись программы SmartPLS и SPSS. Множественные взаимосвязи, существующие между четырьмя предикторными переменными (простота использования, совместимость, полезность и безопасность), изучены с помощью моделирования структурных уравнений (SEM), описывающих удовлетворенность электронным кошельком, продолжительность его использования и демографические переменные.

Результаты показали, что четыре предикторные переменные статистически значимы и подходят для целей исследования. Переменная «совместимость» выступает ведущим фактором в анализе. Вместе с тем усредненные переменные оказались статистически незначимыми.

Итоги исследования помогут поставщикам услуг и маркетологам получить четкое представление о том, что влияет как на само использование электронных кошельков, так и на его (использования) продолжительность. Кроме того, было сделано дополнение к теоретическим выводам о существенной прямой связи между длительным использованием и совместимостью.
\end{abstract}

Ключевые слова: электронный кошелек, количественный, Лайкерт, SmarlPLS, SPSS, моделирование структурных уравнений, многоуровневая регрессия, предикторные переменные.

Научная специальность: 08.00.00 - экономические науки. 